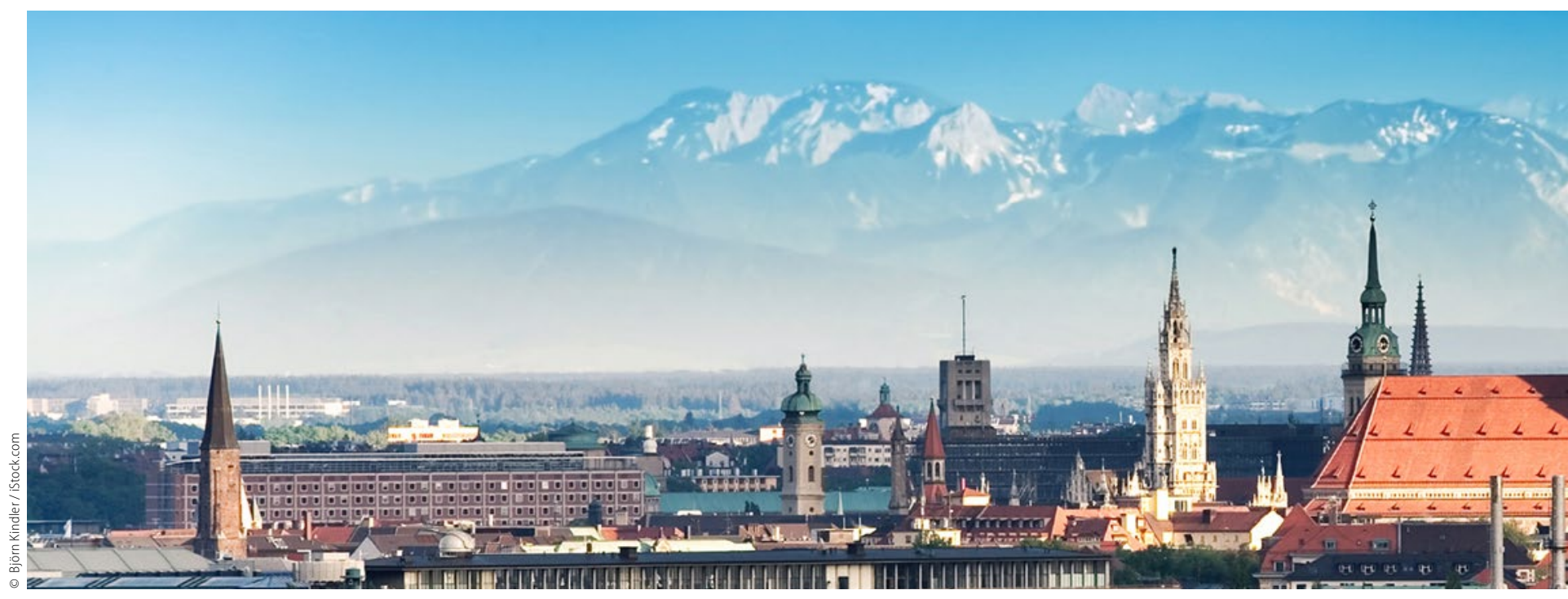

Facettenreiches Halbjahresprogramm

\title{
Stark für Bayern - auch in der Fortbildung
}

\begin{abstract}
Die Zahnräder des Freien Verbands Deutscher Zahnärzte in Bayern symbolisieren Stärke und Zusammenarbeit. "Stark für Bayern" heißt auch das Fortbildungsprogramm des Landesverbands, das er im Januar für das 1. Halbjahr 2016 aufgelegt hat, um Information und Wissen zu vermitteln: preiswert, dezentral und offen für alle Zahnärzte und ihre Praxismitarbeiter in Bayern.
\end{abstract}

„Auf der Höhe der Zeit zu sein, selbst zu gestalten, statt sich nur verwalten zu lassen - das ist unser Ziel für die bayerischen Praxen. Darüber hinaus unterstützen wir Sie auch in diesem Jahr tatkräftig durch die FVDZ-Bayern-Tabelle 2016 und die aktuelle GOZ-Analogliste“, schreibt der Landesvorstand des FVDZ Bayern im Vorwort des Programmhefts.

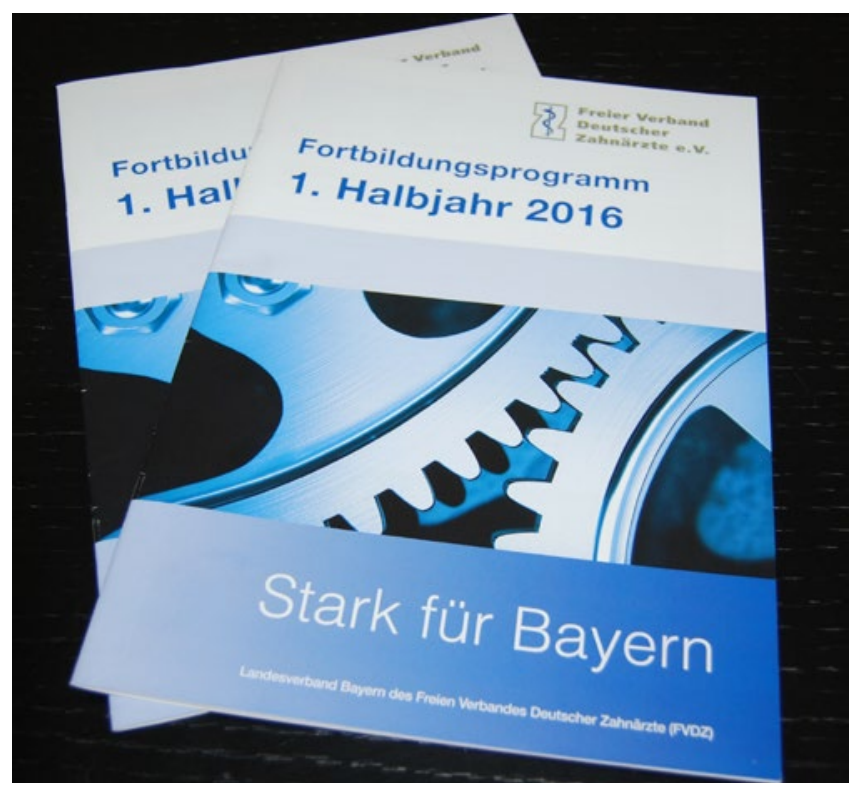

Das Veranstaltungsangebot reicht von Möglichkeiten und Grenzen der zahnärztlichen Chirurgie, Röntgenologie, interdisziplinären Ansätzen bis hin zum Umgang mit HIV und anderen Infektionskrankheiten. Außerdem geht es in einer gut funktionierenden Zahnarztpraxis auch immer um die Faktoren Betriebswirtschaft, Steuern und Marketing. Natürlich nimmt die zahnärztliche Abrechnung einen besonders wichtigen Stellenwert ein. Die Kurse finden in München, Augsburg, Memmingen, Veitshöchheim, Deggendorf, Rosenheim und Lenting statt.

\section{Neue Gesetze, Reformen, Richtlinien}

Zusätzlich zu den Kursen im Programmheft wird der FVDZ Bayern wie jedes Jahr auf die aktuellen Themen aus Berlin und Brüssel reagieren, die die Zahnarztpraxen tangieren: Neue Gesetze, Reformen und Richtlinien werden thematisiert und als Fortbildungsangebot in Form von Seminaren, Workshops oder Vorträgen auf der Internetseite des Landesverbands unter www.fvdz-bayern.de abrufbar und buchbar sein. Aus aktuellem Anlass bietet der FVDZ Bayern Workshops zum Thema Antikorruptionsgesetz im Gesundheitswesen an. Hier geht es um die Fallstricke rund um Materialeinkauf, Labor, Abrechnung.

Dass der FVDZ Bayern dabei auch immer über den zahnärztlichen Tellerrand hinausblickt, ist hinlänglich bekannt. Wie funktionieren beispielsweise Zahnärzte-Bewertungsportale, und was steckt hinter Anbietern wie jameda? Das herauszufinden und die richtigen Schlüsse für die eigene Praxis zu ziehen, will der Landesverband mit seinen Kursen vermitteln.

Anita Wuttke, freie Journalistin 